Printed in Great Britain

\title{
Growth, Cell and Nuclear Divisions in some Bacteria
}

\author{
By M. SCHAECHTER*, JOAN P. WILLIAMSON, J. R. HOOD, Jun., \\ AND A. L. KOCH \\ Departments of Microbiology and Biochemistry, College of Medicine, University \\ of Florida, Gainesville, Florida, U.S.A.
}

(Received 27 December 1961)

\section{SUMMARY}

The timing of cell and nuclear division of certain enteric bacteria was determined under conditions of balanced growth. Organisms were grown in a high refractive index medium and photographed at frequent intervals with a phase-contrast microscope. This allowed an estimation of the time between successive divisions of nuclei and cells (interdivision times) and the growth rate of each individual. The interdivision times of cell and nuclear divisions had a similar degree of variation (coefficients of variation of about $20 \%$ ). The interdivision times of sister cells and sister nuclei were positively correlated to a significant degree. The correlation between mothers and daughters was negative to a significant degree in some, but not all, experiments. The correlation between interdivision times of a cell and that of its corresponding nucleus was positive in most experiments.

The rate of mass increase of individual cells was estimated by measuring the rate of elongation. Within the limitations of the method of observation, it could be concluded that cells grew exponentially between successive divisions. Different individuals grew with very nearly the same rate constant. The variation in size of cells at the time of nuclear and cell division was smaller (coefficients of variation of about $10 \%$ ) than that of the interdivision times.

Some observations on the morphological changes of nuclei during growth and division are presented.

\section{INTRODUCTION}

The time between successive cell divisions varies significantly among individuals in the same culture of certain species of bacteria commonly studied. For this reason, division synchrony must usually be induced by artificial manipulations. This fact has hampered studies of the structural and chemical changes throughout the life span of bacterial cells.

We will call the effective life span of the cell-the time between two successive divisions - the 'cell interdivision time'.

Powell (1958) has suggested that the variability of the cell-division process may be confined to the last stages of cell separation. He suggested that other components of the cell-division cycle may be less variable. We have attempted to investigate this question by timing the interval required for division of bacterial nuclei (the nuclear interdivision time). We have employed the technique of Mason \& Powelson (1956), which permits continuous observation of nuclei in living bacteria. In this technique cells growing in high refractive index media are observed with a

* Present address : Department of Microbiology, Tufts University School of Medicine, Boston, Mass., U.S.A. 
phase-contrast microscope. Under these conditions, the contrast between the nuclei and the cytoplasm is greatly enhanced.

We have compared the timing of nuclear division to that of cell division and to the pattern of growth of individual cells. These data have been used for the construction of a model for the statistics of division processes in bacteria (Koch \& Schaechter, 1962).

\section{MATERIALS AND METHODS}

Growth conditions. The chambers used for observation were prepared as follows: a small drop of an exponentially growing culture of density less than $5 \times 10^{7}$ bacteria/ ml. was placed on the surface of a thin layer of agar containing Trypticase Soy broth, $1.5 \%$ Ionagar (Consolidated Laboratories), and polyvinylpyrrolidone (hereafter, PVP) in amounts varying between 23 and $27 \%$. One half to one hour later the drop was spread over a portion of the agar surface with a bent rod. A block of agar about $7 \mathrm{~mm}$. square was cut out, placed on a glass slide, and covered with a $22 \mathrm{~mm}$. square no. 0 cover-glass. Slides and cover-glasses were cleaned by prolonged immersion in fuming nitric acid, rinsing in distilled water, and air drying. The edges of the preparations were sealed with a paraffin-beeswax mixture to prevent drying. All manipulations were carried out at $37^{\circ}$ in an incubator room.

Microscopy. All observations were done with a Wild phase-contrast microscope enclosed in a plastic chamber maintained at $37^{\circ}$. As little light as possible was used. Pictures were taken with $\mathbf{3 5} \mathrm{mm}$. Kodak High Contrast film which was processed with D-19 developer. Enlargements were made on Kodabromide F-5 contrast paper. Contrast on the prints was considerably higher than by direct observation.

Evaluation of the photographs. The measurements of interdivision time were obtained from photographic prints. Cell lengths were measured with calipers on projections of the photographic films. In most experiments pictures were taken every 1 or $2 \mathrm{~min}$., in some every 2 or $3 \mathrm{~min}$.

The criteria used for establishing when cells and nuclei had divided were, of necessity, subjective. Cell division was considered to be completed when the cells' adjoining ends appeared to be fully hemispherical. It was judged that a nucleus had divided when the two resulting bodies were clearly individualized and no nuclear material could be seen between them. Using these criteria, cell and nuclear division probably terminated before the time assigned by the observer. Such systematic errors in scoring, by themselves, would not lead to errors in the interdivision times. After some experience the time of cell or nuclear division could be estimated with a variation no greater than 2-4 min., that is, within one or two pictures. In less than $10 \%$ of the cases this uncertainty extended itself over as much as $12 \mathrm{~min}$. Despite the subjectivity of the evaluation, the results obtained were quite reproducible. Series obtained earlier in the work were re-evaluated after several months. Close agreement of all measurements was obtained on repeated evaluation by the same or a different observer.

Bacterial strains. Some smooth colonies of Escherichia coli strain B/r when illuminated by indirect light showed radial striations characteristic of rough strains. From such a colony a mutant which showed rougher colonies was isolated and designated $\boldsymbol{E}$. coli $\mathrm{B} / \mathrm{r}$ (rough). Proteus vulgaris and Salmonella typhimurium LT-2 colonies were smooth. 


\section{RESULTS}

The growth of single cells. The data employed in the present work were derived from populations undergoing balanced growth, as determined by the following criteria: (1) Exponential increase of the number of cells and nuclei in the field. (2) Constancy of the mean cell size. (3) Close agreement between the mean cell and nuclear interdivision times and the mean doubling time determined independently from the increase in numbers for the entire field. (4) When measured, maintenance of the same rate of elongation by individual cells and their descendants.

Balanced growth was originally defined in a stricter fashion (growth resulting in a proportional increase of every extensive cellular property in the same period of time; Campbell, 1957). We feel that compliance with the criteria employed is a strong indication that growth was indeed balanced.

The period of observation extended over three to four mean doubling times. Thereafter, the microscopic fields became too crowded for careful measurements. About ten cells were present at the beginning of the period of observation in the portion of the field included in the photographic frame. The data reported are derived from scoring two consecutive divisions and include the entire progeny of the original individuals. This procedure avoids the discussed bias due to an arbitrary cut-off of the period of observation, by Powell (1955).

Some experiments were not included because growth was unbalanced. Here cell division either proceeded at a progressively slower rate, or was synchronized to a higher degree than expected from random sampling of small numbers of cells.

The rate of growth (expressed as the mean doubling time in minutes) was estimated from the increase in the number of cells. The mean doubling time for Salmonella typhimurium on PVP-agar (31-35 min.) was slower than on agar without PVP (Table 1), but was the same as in aerated Trypticase Soy broth (without PVP) cultures. The mean doubling time of Escherichia coli B/r growing on PVP-agar (26-32 min.) was slower than either in broth without PVP or on agar without PVP, where it was $18-20 \mathrm{~min}$. These differences were probably due to the physical conditions of cultivation.

The rate of elongation of Escherichia coli $\mathrm{B} / \mathrm{r}$ and Salmonella typhimurium was estimated from measurements of length of individual cells during growth. As can be seen from Fig. 1, cells increased in length at all times during the division cycle, without noticeable discontinuities. Similar plots were obtained when the lengths of the progeny cells were summed over two or three divisions. The shape of the curve varied slightly between individual cells. However, this variation was independent of the size of the cells at division, since large and small cells elongated with approximately the same rate constant. It was very difficult to obtain exact measurements since, in addition to the limitations in the resolution of the microscope, errors were introduced by curvature of the cells or differences in focal plane. For this reason it was not possible to determine the precise mode of elongation between cell divisions. None the less, our measurements were consistent with the hypothesis that elongation was proportional to the length of the cells, i.e. that all cells grew exponentially with the same growth rate constant. It must be kept in mind that an exponential line and a straight line differ only slightly over one doubling. The diameter of the cells was not measured but did not appear to vary perceptibly during growth. Data 
M. Schatehter AND OTHERS

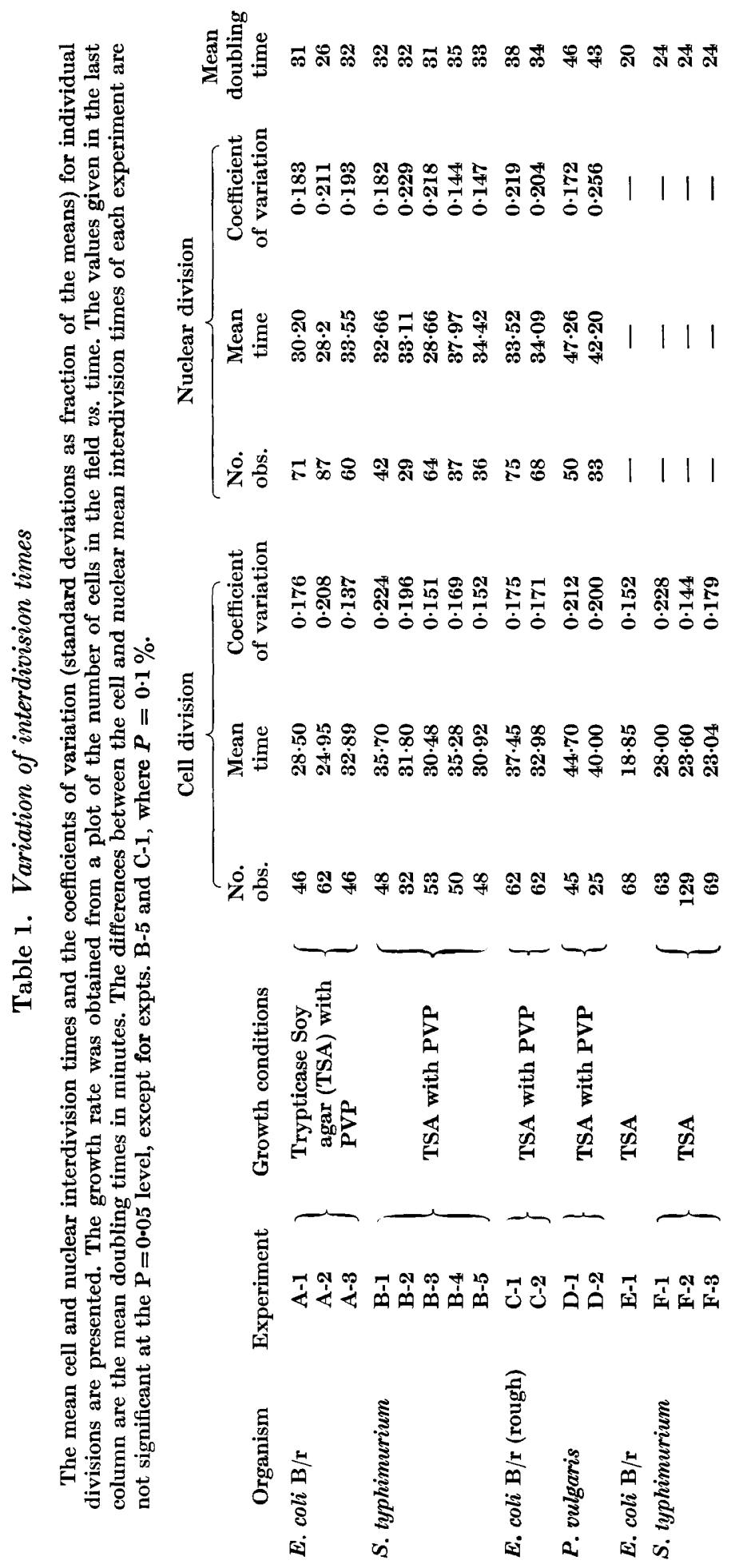


presented by other authors indicate that this dimension remains approximately constant during the development of individual cells (Adolph \& Bayne-Jones, 1932; Deering, 1958; Maclean \& Munson, 1961). The apparent refractive index of the cells also remained constant during their development. Measurement of the refractive index with the interference microscope has shown little variation among individuals

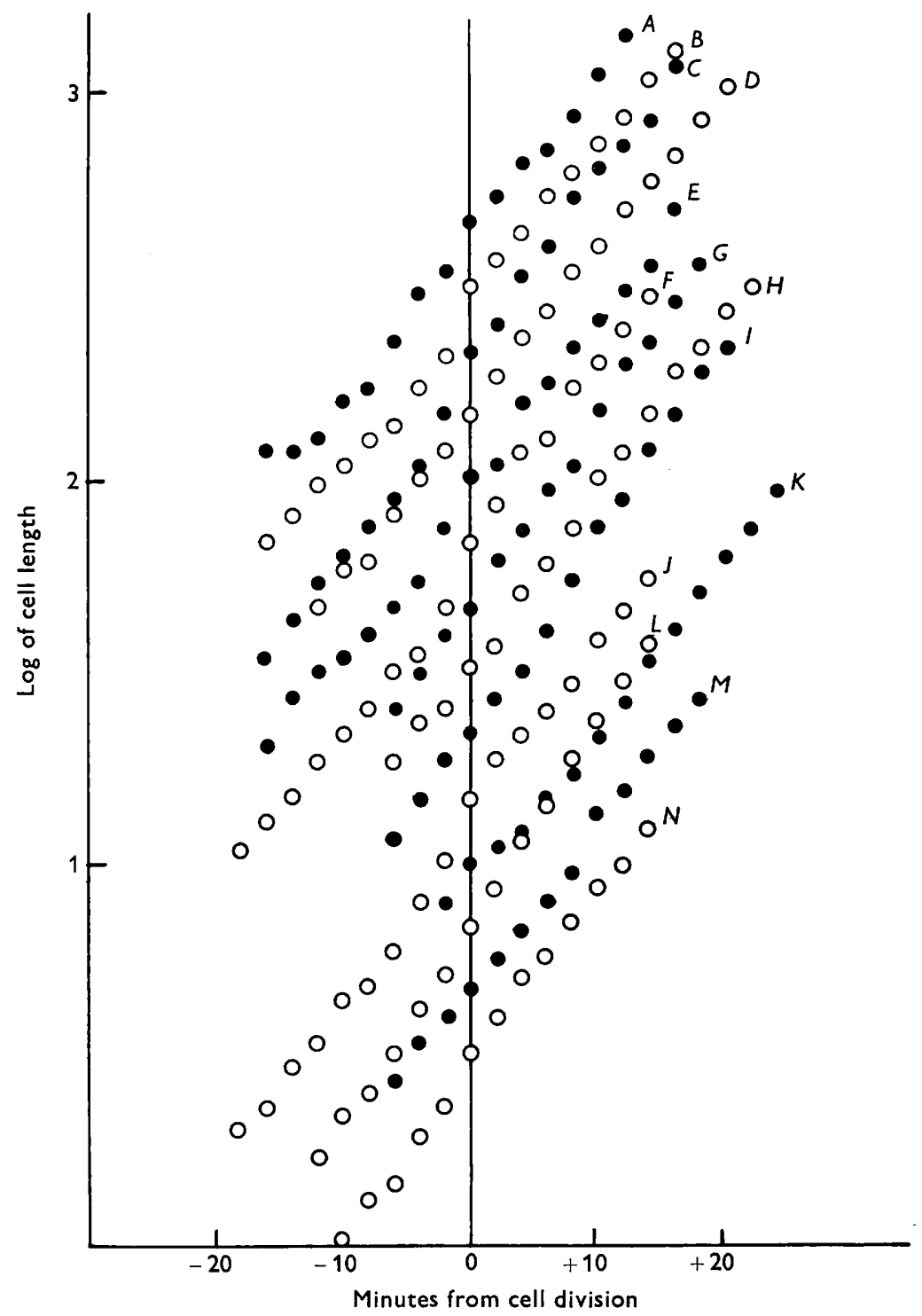

Fig. 1. Elongation of individual cells. The length of $E$. coli $\mathrm{B} / \mathbf{r}$ cells (Expt. E-1) was measured every 2 min. The length of the resulting daughter cells was added. The measurements are presented in the following manner: the logarithm of cell length in arbitrary units is plotted along the ordinate. Zero on the abscissa represents the time of division. The size at division of individual cells is spaced at equal intervals along the ordinate. The length of the cells at the time of division was (in alphabetical order): $4 \cdot 1,4 \cdot 9,5 \cdot 0$, $5 \cdot 1,5 \cdot 1,5 \cdot 2,5 \cdot 4,5 \cdot 5,5 \cdot 7,5 \cdot 7,5 \cdot 8,5 \cdot 9$, and $6 \cdot 0 \mu$. 
of different ages (Ross, 1957). Therefore, cell elongation was considered to represent a reasonable measure of the increase in cell mass.

Nuclear morphology in growing cells. Plate 1, fig. 1, shows a series of photographs of Escherichia coli $\mathrm{B} / \mathrm{r}$ and Salmonella typhimurium taken from sequences used in the evaluation of nuclear interdivision times. These particular pictures were considered typical of the morphological events commonly seen. The changes associated with development and division of the nuclei were similar to those described for stained preparations (e.g. Murray, 1960), and ultra-thin sections (Robinow, 1962). We have not been able to generalize on the morphology of nuclear division because variations in individual nuclei prevented simple interpretations. These variations may be caused by gyrations of the nuclei and divisions along different planes. None the less, we usually observed the following pattern in $E$. coli B/r, S. typhimurium, and Proteus vulgaris. The most compact and spherical appearance of the nuclei was seen shortly after they had divided and begun to migrate towards opposite poles of the cell. The majority of nuclei remained in this condensed form for about one-third of the interdivision time. Thereafter they assumed a variety of complex patterns with a predominance of elliptical, dumbbell and V-shapes. The first indications of the separation of daughter nuclei were usually given by elongation of the mother structure, followed by narrowing of its central portion. This region became thinner as the daughter nuclei separated and appeared more compact. In some cases the separation process was not along the major but the minor axis of the cell. Here sister nuclei in the later stages of separation were oblong and situated side by side. Final separation occurred when these structures slid past one another towards opposite poles.

With most nuclei, the final stages of separation took place quite rapidly. For this reason, the period of uncertainty in scoring the time at which nuclear division occurred usually covered less than $10 \%$ of the mean interdivision time. However, in about $5 \%$ of the cases the resulting nuclei were connected for a long time by strands of material of the same optical properties as nuclear material.

Plate 2, fig. 2, shows sequences of Escherichia coli 15T-. It can be seen that these organisms are considerably larger than those shown in Pl. 1, fig. 1, and that the nuclear configurations are more complex. The compact post-division configuration is seen only rarely, and then for brief times. These nuclei were markedly lobate practically throughout the division cycle. In these cells it was not possible to evaluate the nuclear interdivision times with sufficient accuracy. For this reason, no interdivision time data are presented for $E$. coli $15 \mathrm{~T}$-.

Other strains of Escherichia coli also showed nuclear morphology which differed from that of the B/r strain. For example, in $E$. coli K-12 (C600, F-) which is composed of short, rounded cells, nuclei almost always divided along the minor axis of the cell. For a considerable portion of the division cycle many cells showed nuclei shaped like coffee beans. These nuclei also separated by sliding past one another towards the poles of the cells.

Distribution of cell and nuclear interdivision times. Each experiment dealt with 20-80 individual nuclear and cell divisions. Despite careful adherence to balanced growth techniques, the growth rate varied somewhat between experiments with the same strain. The coefficients of variation (standard deviation as a fraction of the mean interdivision times) were approximately $0 \cdot 2$ within individual experiments. 
Sheppard's correction for grouping decreased the variance by a small amount, ranging from about 1 to $4 \%$. The standard deviations of the interdivision times were considerably higher than the average time for nuclei or cells to become clearly separated. Thus, it is probable that the true coefficients of variation are not much smaller than those estimated.

The distributions of cell and nuclear interdivision times are shown in Fig. 2 for Escherichia coli B/r and Fig. 3 for Salmonella typhimurium. They represent pooled data from the experiments shown in Table 1. The estimates of the third moment of distribution, $g_{1}$, and their standard deviations are presented in Table 2. This estimate is a measure of skewness of the distribution (Fisher, 1948). In all cases

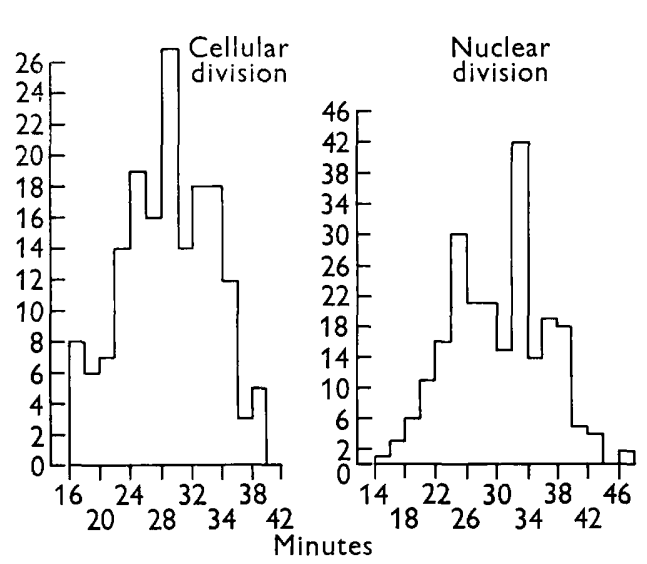

Fig. 2

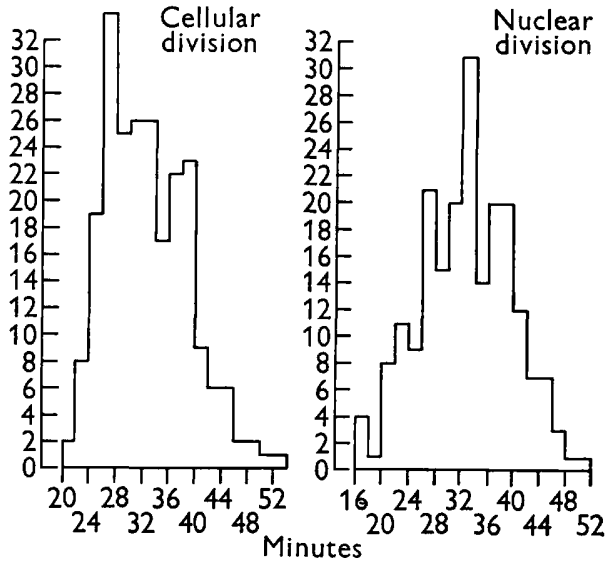

Fig. 3

Fig. 2. Frequency distributions of nuclear and cell interdivision times of Escherichia coli.

Fig. 3. Frequency distribution of nuclear and cell interdivision times of Salmonella typhimurium.

Table 2. Skewness statistics of interdivision time distributions $g_{1}$ is an estimate of the third moment of distribution and is a measure of skewness.

\begin{tabular}{|c|c|c|c|c|c|}
\hline Organism & No. obs. & Mean & $\begin{array}{l}\text { Standard } \\
\text { deviation }\end{array}$ & $g_{1}$ & $\begin{array}{l}\text { deviation } \\
\text { of } g_{1}\end{array}$ \\
\hline \multicolumn{6}{|c|}{ Cell division } \\
\hline richia coli $\mathrm{B} / \mathrm{r}$ & 154 & $28 \cdot 4$ & $5 \cdot 93$ & 0.005 & $0 \cdot 197$ \\
\hline onella typhimurium & 231 & $32 \cdot 7$ & $6 \cdot 24$ & $0 \cdot 566$ & $0 \cdot 160$ \\
\hline us vulgaris & 70 & $43 \cdot 5$ & $9 \cdot 62$ & $0 \cdot 145$ & 0.287 \\
\hline \multicolumn{6}{|c|}{ Nuclear division } \\
\hline erichia coli $\mathrm{B} / \mathbf{r}$ & 218 & $\mathbf{3 0} \cdot \mathbf{3}$ & $6 \cdot 34$ & $0 \cdot 145$ & $0 \cdot 165$ \\
\hline onella typhimurium & 208 & $32 \cdot 8$ & $7 \cdot 02$ & $-0 \cdot 039$ & $0 \cdot 169$ \\
\hline us vulgaris & 82 & $45 \cdot 9$ & $9 \cdot 61$ & -0.261 & $0 \cdot 266$ \\
\hline
\end{tabular}

except cell interdivision times of $S$. typhimurium, $g_{1}$ is not significantly larger than its standard deviation. Therefore, with the exception noted, these distributions are not significantly skewed. These computations were performed on data pooled from experiments with different means. However, the same conclusions were reached 
by examining pooled individual experiments, or by pooling after normalizing the variation in means and standard deviations of individual experiments.

Since the addition of PVP to the agar resulted in slower growth, we have also estimated the dispersion of cell interdivision times in the absence of this substance. The coefficients of variation (Table 1) are similar to those obtained from growth on PVP. Thus, growth under the conditions used for observation of nuclear divisions did not significantly alter the variability of cell interdivision times.

Length of cells at the time of cell and nuclear division. As can be seen in Table 3, the coefficients of variation of the length of cells at the time of division were of the order of $0 \cdot 1$. In most cases the cells divided into apparently equal halves. Infrequently, a measurable difference between the lengths of the two daughter cells could be seen. However, the resolution of the measurements was insufficient to permit a meaningful estimate of the distribution of this difference.

Table 3 also shows that the coefficient of variation of the length of cells at the time of nuclear division was small and of the same magnitude as that of lengths of cells at cell division.

Correlation between estimates of individual interdivision times. Cells or nuclei engendered by the same division were termed 'sisters' when compared with each other, and 'daughters' when related to the 'mother' structure from which they arose. As shown in Table 4, the interdivision times of sister cells and sister nuclei showed a significant positive correlation (measured by the intraclass correlation, Yule \& Kendall, (1948)), according to the following formula:

$$
r=\frac{2\left(s_{m}^{2}\right)-s^{2}}{s^{2}},
$$

where $s_{m}^{2}$ is the variance of the means of each pair and $s^{2}$ the variance of all measurements). The plot of sister cells and sister nuclei interdivision times of a typical experiment is shown in Fig. 4.

Correlation between interdivision times of mother and daughter structures was negative in most experiments. However, in several cases it did not significantly differ from zero. Data from an experiment with $\boldsymbol{E}$. coli $\mathrm{B} / \mathrm{r}$ are shown in Fig. 5 .

As discussed by Powell (1958) and Koch \& Schaechter (1962), random errors in the estimation of the times of division tend to make the correlation coefficients between sisters closer to 0.5 and between mothers and daughters closer to -0.5 . It should be noted that many points on the sister versus sister diagrams lie exactly on a 45 degree line. This is due in part to grouping, since observations were not carried out continuously but at definite intervals. Furthermore, there was probably also an artifact of evaluation, since if division of two sisters was nearly simultaneous, the observer was likely to score their division at the same time. Although this bias is small and will not affect the mean values, it tends to make the sister-sister correlation closer to $\mathbf{1} \cdot \mathbf{0}$.

The estimated mother-daughter correlation varied in different experiments with the same strain. Therefore, it was difficult to establish if these correlation coefficients were significantly below zero. The observed values were, in general, more negative than those previously reported (Powell, 1958; Kubitschek, 1962). An example of this correlation is given in Fig. 5.

We have also estimated the correlation between the nuclear and the cell inter- 
Table 3. Length of cells at the time of cell and nuclear division

The designation of individual experiments is the same as in Table 1.

\begin{tabular}{|c|c|c|c|c|c|c|c|}
\hline \multirow[b]{2}{*}{ Organism } & \multirow[b]{2}{*}{ Experiment } & \multicolumn{3}{|c|}{ Length at cell division } & \multicolumn{3}{|c|}{ Length at nuclear division } \\
\hline & & $\begin{array}{l}\text { Number } \\
\text { measured }\end{array}$ & $\begin{array}{c}\text { Mean } \\
\text { length } \\
\text { in } \mu\end{array}$ & $\begin{array}{c}\text { Coefficient } \\
\text { of } \\
\text { variation }\end{array}$ & $\begin{array}{l}\text { Number } \\
\text { measured }\end{array}$ & $\begin{array}{l}\text { Mean } \\
\text { length } \\
\text { in } \mu\end{array}$ & $\begin{array}{c}\text { Coefficient } \\
\text { of } \\
\text { variation }\end{array}$ \\
\hline Escherichia coli $\mathbf{B} / \mathbf{r}$ & $\begin{array}{l}\text { A-1 } \\
\text { A-3 }\end{array}$ & $\begin{array}{l}37 \\
22\end{array}$ & $\begin{array}{l}5 \cdot 1 \\
4 \cdot 3\end{array}$ & $\begin{array}{l}0.085 \\
0.089\end{array}$ & $\begin{array}{l}44 \\
45\end{array}$ & $\begin{array}{l}3 \cdot 9 \\
3 \cdot 3\end{array}$ & $\begin{array}{l}0.095 \\
0.093\end{array}$ \\
\hline $\begin{array}{l}\text { Salmonella } \\
\quad \text { typhimurium }\end{array}$ & $\begin{array}{l}\text { B-4 } \\
\text { B-5 } \\
\text { F-1 } \\
\text { F-2 } \\
\text { F-3 }\end{array}$ & $\begin{array}{l}54 \\
24 \\
73 \\
69 \\
19\end{array}$ & $\begin{array}{l}3 \cdot 7 \\
4 \cdot 3 \\
4 \cdot 7 \\
4 \cdot 5 \\
5 \cdot 4\end{array}$ & $\begin{array}{l}0 \cdot 099 \\
0 \cdot 107 \\
0 \cdot 118 \\
0 \cdot 130 \\
0 \cdot 090\end{array}$ & $\begin{array}{l}37 \\
22 \\
- \\
- \\
-\end{array}$ & $\begin{array}{l}3 \cdot 2 \\
3 \cdot 4 \\
- \\
- \\
-\end{array}$ & $\begin{array}{c}0.099 \\
0.063 \\
- \\
- \\
-\end{array}$ \\
\hline
\end{tabular}
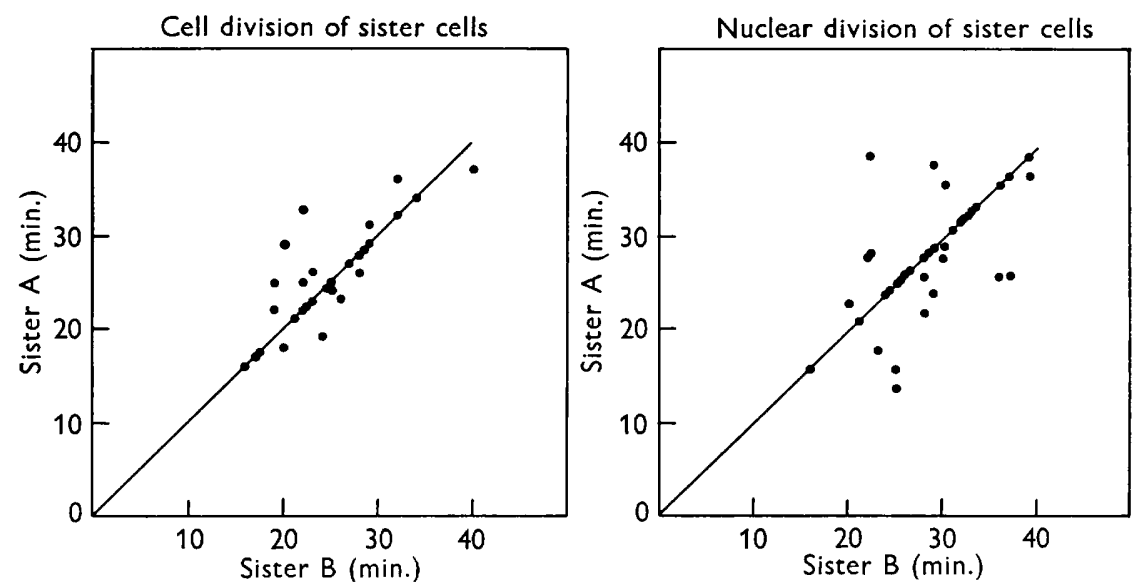

Fig. 4. Correlations of interdivision times of sister cells and sister nuclei. The data were obtained with Escherichia coli B/r (Expt. A-2). The coefficients of intraclass correlation were 0.628 and 0.622 for cell and nuclear division, respectively. The line represents the expectation for identical interdivision times of sisters. Possible reasons for the fact that many points appear to lie precisely on this line are given in the text.
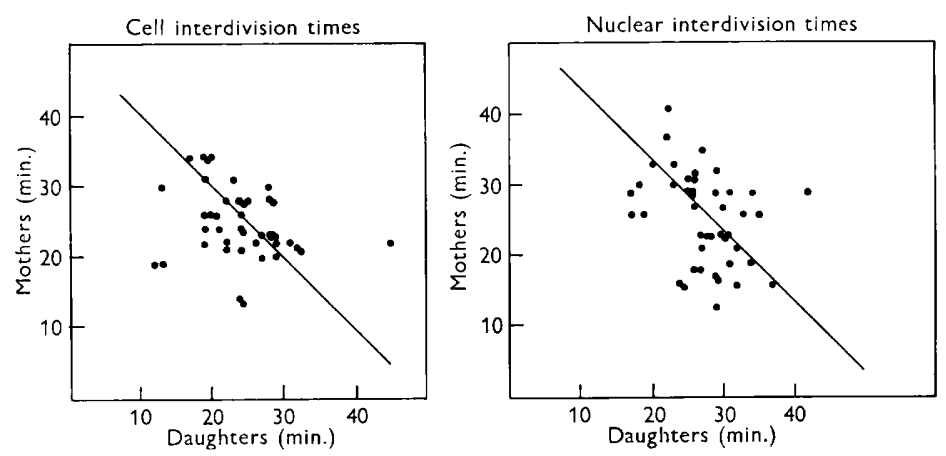

Fig. 5. Correlation of nuclear and cell interdivision times of mothers and daughters. The data were obtained with Escherichia coli B/r (Expt. A-2). The coefficients of correlation were $-0 \cdot 542$ and -0.336 for cell and nuclear division respectively. The line represents the expectation for a constant time span between inception of a mother and division of daughters. 


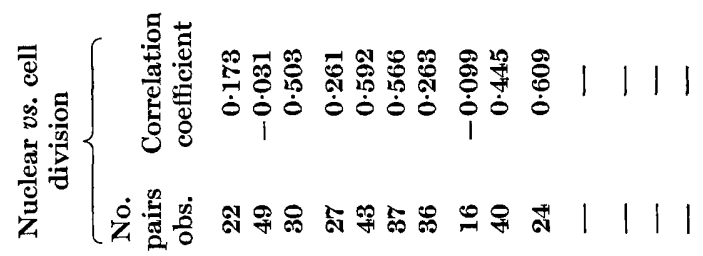
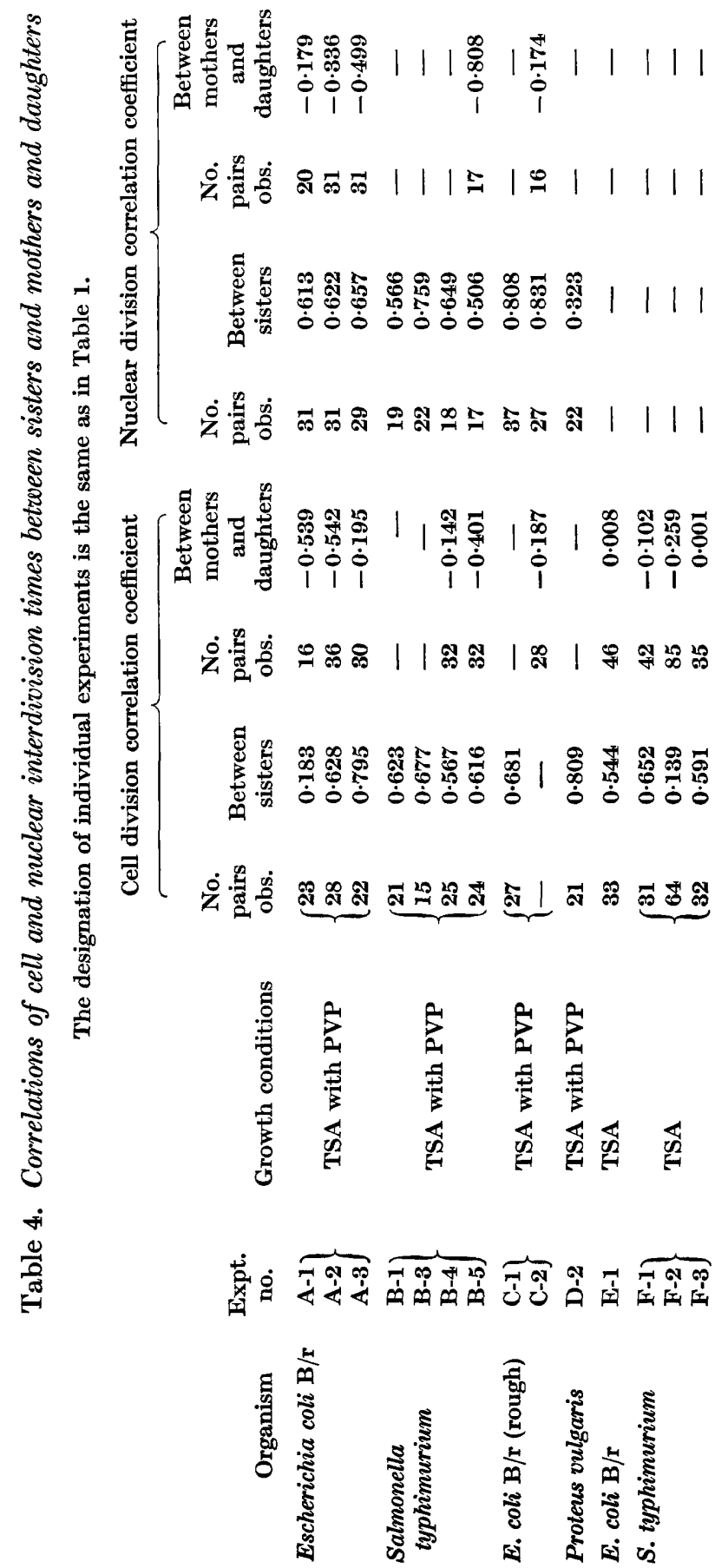
division times of the same individual. As shown in Table 4, the interdivision times of these two processes were positively correlated in all but two experiments. In all the species studied, the interval between cell and nuclear division, as well as that between nuclear and cell division, had coefficients of variation of $0 \cdot 4-0 \cdot 6$. The standard deviation in minutes was comparable to that of the interdivision times. Despite this variability, cell division took place before the subsequent nuclear division in at least $99 \%$ of the cases. That is, less than $1 \%$ of the cells contained four nuclei at any time.

\section{DISCUSSION}

The purpose of the present work was to relate some aspects of cell and nuclear division to the normal growth process. To this end it was necessary to obtain data on the timing of the division processes and on the growth of individual cells. Some results are similar to those previously published. Others are original and obtained by the application of newer methods of observation.

Cell growth was found to take place throughout the division cycle. There have been no indications of deceleration immediately before division, as reported for Streptococcus faecalis (Mitchison, 1961). Exponential growth of single cells of several rod-shaped bacteria has been previously reported (Schmalhausen \& Bordzilowskaja, 1930; Adolph \& Bayne-Jones, 1932; Bayne-Jones \& Adolph, 1933). In so far as the technical limitations allow, our data also suggest that growth is exponential throughout the division cycle of the organisms studied. If the rate of growth is indeed proportional to the cellular mass, strong support would be obtained for the previous assertion (Schaechter, Maaløe \& Kjeldgaard, 1958; Neidhardt \& Magasanik, 1960; Kennell \& Magasanik, 1962) that protein synthesizing units perform at constant efficiency. It was found by these workers that the rate of protein synthesis is directly proportional to the amount of ribosomes present in bacteria growing under a variety of conditions. Quantitatively, growth is more directly expressed by the synthesis of proteins than by that of any other class of compounds, since proteins constitute about one half the dry weight of bacterial cells. Continuous exponential growth may then be the result of the fact that ribosomes synthesize proteins at a constant rate at all times in the life of the cell.

Our results on the spread of the distribution of cell interdivision times agree in general with those previously obtained by Kelly \& Rahn (1932), Powell (1958) and Kubitschek (1962). The degree of variation of the process is similar in all these reports. However, in contrast to their observations, we have not found that the frequency distributions obtained, with the exception of Salmonella typhimurium cell interdivision times, are significantly skewed. This is of some significance since several theoretical models based on the statistics of a small number of molecular events would account for skewness in the distribution (Rahn, 1931; Kendall, 1948). The discrepancy between the shape of the distributions reported by others and that found by ourselves may reflect differences in the strains or in the techniques employed. It is worth emphasizing that unequivocal data cannot be obtained because of the lack of precision in the methods and the relatively small number of observations which can be made within each experiment.

The observations on nuclear division were made with a technique that has not been extensively used and which is not entirely understood. These data must, 
therefore, be interpreted with due caution. The technique used may be subject to the following limitations. First, the resolution of the light microscope does not permit precise, unequivocal discernment of the actual time of nuclear division. The extent to which this introduces systematic or random errors is not known. Secondly, the optical relationship between nuclei and cytoplasm may not clearly differentiate these structures at all times. If what is observed at different times during the division cycle is not the whole nucleus or only the nucleus, the scoring of the nuclear interdivision times would be incorrect. However, the similarity between the nuclear morphology observed by this technique and that seen in stained preparations makes it unlikely that our results were greatly influenced by these sources of error. At the present, the timing of nuclear division cannot be independently verified by other methods.

In several respects, the timing of nuclear and cell division is similar. Thus, the following features are comparable in the two processes: the coefficient of variation of the interdivision time, the coefficient of correlation between sisters, and the - coefficient of correlation between mothers and daughters. However, nuclear division does not directly trigger cell division, or vice versa, since the interval between the two processes is as variable as the interdivision times. A similar finding was reported by Mitchison (1961) in Streptococcus faecalis.

In the bacteria studied, the nucleus commonly divides in the middle third of the cell-division cycle. In this, bacteria differ from many types of animal and plant cells, where karyokinesis is soon followed by cytokinesis. Despite the proportionately long and varied interval of time between them, the two division processes must be related in some fashion since the frequency of two successive nuclear divisions without an intervening cell division, and vice versa, is very small. Indeed, it is less than what would be expected by chance if both processes were normally distributed (approximately $5 \%$ ). This is also seen in our finding that, in general, the cell and nuclear interdivision times are positively correlated. Both cell and nuclear division are more closely correlated to the size which the cell has attained than to the time when the previous division took place. This 'critical size' is different for the two division processes, and in both cases is subject to small, uncorrelated random variations. The various statistical correlations between the two processes can be explained on the basis of these variations (as discussed below).

Some strains of bacteria grow in filaments which divide in an almost random fashion. In these cases, nuclear division and cell division are certainly uncorrelated. It is of interest to note that photomicrographs by Mason (Murray, 1960) of a growing Escherichia coli filament show that the interdivision times of the individual nuclei contained in a common cytoplasm vary to a significant degree.

In the accompanying report (Koch \& Schaechter, 1962), a model of cell division is proposed. It is based mainly on the present experimental findings. The model postulates: (1) that mass growth of individual cells is exponential and proceeds at substantially the same rate that characterizes the whole population; (2) that cell size at division, or some closely related property, is under close physiological control; (3) that the size of cells at division is nearly the same for all individuals, i.e. the coefficient of variation of the size at the time of division is small; (4) that cell division results in daughters which are nearly equal in size. Also inherent in the model is lack of correlation between the size at one division and at the next. 
Although no consideration is given in the accompanying paper to nuclear division, the same conclusions should apply to this process as well. This is because nuclear division, much like cell division, seemingly takes place when the cytoplasm has reached a particular size. The other postulates refer to properties of the cell and apply equally to cell and nuclear diviston.

From these assumptions, a coefficient of variation of the interdivision times of about 0.20 (Table 1 ) is explained on the basis of the observed $0 \cdot 10$ coefficient of variation of the size at division (Table 3 ). If cell division results in daughters of precisely equal size, the model predicts that sister-sister interdivision times correlation coefficients be 0.5 and that mother-daughter coefficients be $-\mathbf{0 . 5}$. In most experiments (Table 4), the observed values are somewhat more positive for both parameters. Although unequal division of the other cell would render the motherdaughter coefficients more positive, it would also tend to decrease the sister-sister correlations. Therefore, these measurements do not speak for asymmetry of cell division. Another experimental finding which agrees with this conclusion is the lack of gross asymmetry in the interdivision time distribution. It was shown by Koch \& Schaechter (1962) that unequal division is one cause of asymmetry in this distribution. Other possible sources of deviation from the expected values have been discussed (Koch \& Schaechter, 1962).

The general agreement between the data and the predictions of the theory supports the conclusion that fluctuations in the size at one division are uncorrelated with the fluctuations in size at the previous cell or nuclear division, as well as with fluctuations in the division of the sister structure.

As Powell (1958) has pointed out, the separation of daughter cells may be influenced by biologically trivial factors whose effect would be exerted after more fundamental and more regular processes of replication have taken place. However, for many experimental studies which depend on the actual number of individual cells or nuclei, it is irrelevant if the division processes depend solely on physiologically cogent factors, or are influenced by environmental accidents.

The present work further indicates that the cell-division cycle in certain bacteria is experimentally elusive. Our finding that nuclear division is subject to individual variations further emphasizes these difficulties. From these considerations it follows (as has already been stated by Campbell (1957) and Maaløe (1962)) that synchronization of cell division in bacteria is not usually achieved without the introduction of artificial conditions.

We wish to thank Dr R. E. Hoffman for help in the statistical aspects of this work.

This investigation was supported by the following research grants: E-2744 from the National Institute of Allergy and Infectious Diseases, U.S. Public Health Service, C-3255 from the National Cancer Institute, U.S. Public Health Service, and NSFG 8851 from the National Science Foundation. It was also supported by a Senior Research Fellowship, GSF-4333 from the U.S. Public Health Service to the first author.

\section{REFERENCES}

Adolph, E. F. \& Bayne-Jones, S. (1932). Growth in size of micro-organisms measured from motion pictures. II. Bacillus megatherium. J. cell. comp. Physiol. 1, 409.

Bayne-Jones, S. \& Adolph, E. F. (1933). Growth in size of micro-organisms measured from motion pictures. III. Bacterium coli. J. cell. comp. Physiol. 2, 329. 
Campredu, A. (1957). Synchronization of cell division. Bact. Rev. 21, 263.

DeEring, R. A. (1958). Studies on division inhibition and filament formation of Escherichia coli by ultraviolet light. J. Bact. 76, 123.

Fisher, R. A. (1948). Statistical Methods for Research Workers, 10th ed., pp. 54, 72. New York: Hafner Publishing Co. Inc.

Kelly, C. D. \& RAHN, O. (1932). The growth rate of individual bacterial cells. J. Bact. 23, 147.

KenDaLl, D. G. (1948). On the role of variable generation time in the development of a stochastic birth process. Biometrika, 35, 316.

Kennell, D. \& MAGasanik, B. (1962). The relation of ribosome content to the rate of enzyme synthesis in Aerobacter aerogenes. Biochim. biophys. Acta. 55, 139.

Koch, A. L. \& Schaechter, M. (1962). A model for the statistics of the cell division process. (In the Press.)

KubitscheK, H. E. (1962). Normal distribution of cell generation rate. Exp. Cell. Res. 26, 439.

MAALøE, O. (1962). Synchronous growth. In The Bacteria, vol. 4, ch. 3. Ed. by I. C. Gunsalus and R. Y. Stanier. New York: Academic Press.

Maclean, F. I. \& Munson, R. J. (1961). Some environmental factors affecting the length of Escherichia coli organisms in continuous cultures. J. gen. Microbiol. 25, 17.

Mason, D. J \& Powelson, D. M. (1956). Nuclear division as observed in live bacteria by a new technique. J. Bact. 71, 474.

Mrtchison, J. M. (1961). The growth of single cells. III. Streptococcus faecalis. Exp. Cell Res. 22, 208.

Murray, R. G. E. (1960). The internal structure of the cell. In The Bacteria, Vol. 2, p. 35. Ed. by I. C. Gunsalus \& R. Y. Stanier. New York: Academic Press.

Neidhard, F. C. \& Magasanik, B. (1960). Studies on the role of ribonucleic acid in the growth of bacteria. Biochim. biophys. Acta, 42, 99.

Powell, E. O. (1955). Some features of the generation times of individual bacteria. Biometrika, 42, 16.

Powell, E. O. (1958). An outline of the pattern of bacterial generation times. J. gen. Microbiol. 18, 382.

RAHN, O. (1931). A chemical explanation of the variability of the growth rate. J. gen. Physiol. 15, 257.

Robinow, C. F. (1962). Morphology of the bacterial nucleus. Brit. med. Bull. 18, 31.

Ross, K. F. A. (1957). The size of living bacteria. Quart. J. micr. Sci. 98, 435.

Schaechter, M., MaAløe, O. \& KJeldgaard, N. O. (1958). Dependence on medium and temperature of cell size and chemical composition during balanced growth of Salmonella typhimurium. J. gen. Microbiol. 19, 592.

Schmaltausen, I. \& BordzilowskaJa, N. (1930). Das Wachstum niederer Organismen. I. Das individuelle Wachstum der Bakterien und Hefen. Roux Arch. Entwmech. Organ. $121,726$.

Yule, G. U. \& Kendall, M. G. (1948). An Introduction to the Theory of Statistics, 13th ed. p. 253. London: C. Griffin and Co. Ltd.

\section{EXPLANATION OF PLATE}

Plate 1

Fig. 1. Excerpts from photographic sequences of cells growing on PVP-agar. The three rows are (from top to bottom): Salmonella typhimurium, Escherichia coli $\mathrm{B} / \mathrm{r}$, and $E$. coli $\mathrm{B} / \mathrm{r}$ (rough). The figures above each picture represent the time in minutes since the beginning of observation. Contrast was reversed photographically.

Fig. 2. As in fig. 1. These pictures are of Escherichia coli 15T-. The complex morphology of the nuclei in this strain did not permit precise evaluation of the interdivision time. 
Journal of General Microbiology, Vol. 29, No. 3

Plate 1

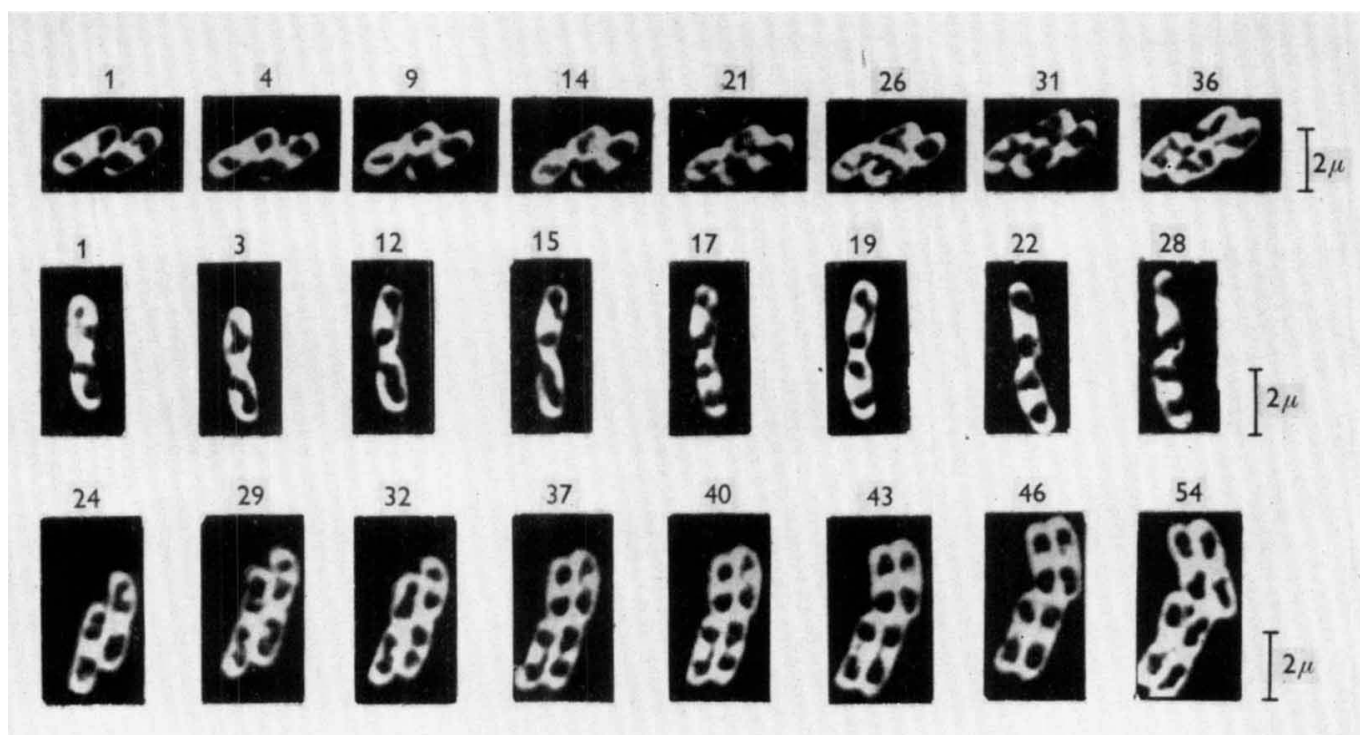

Fig. 1
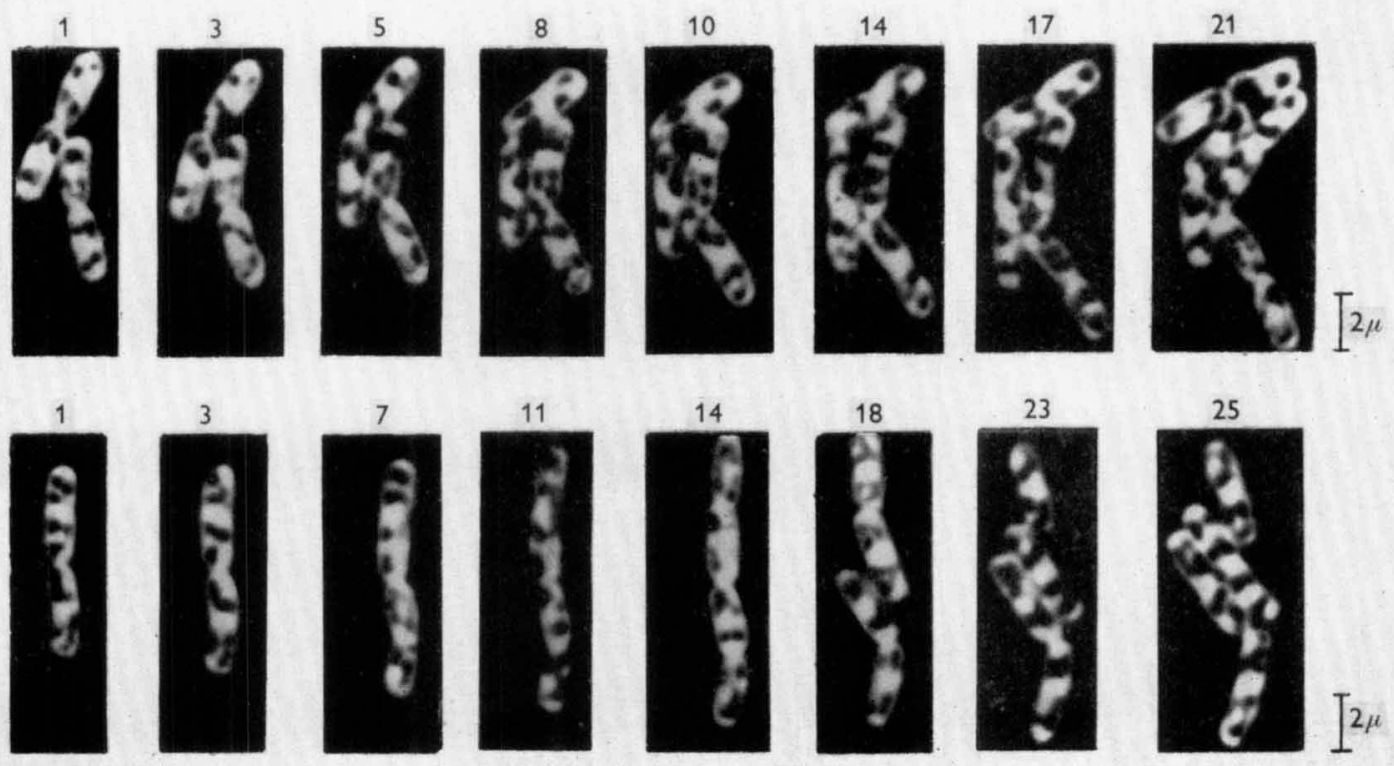

Fig. 2 